\title{
How Equitable Is Health Spending On Curative Services And Institutional Delivery In Malawi? Evidence From A Quasi- Longitudinal Benefit Incidence Analysis
}

\author{
Martin Rudasingwa \\ Heidelberg University \\ Edmund Yeboah \\ Heidelberg University \\ Valéry Ridde \\ French National Research Agency: Agence nationale de la recherche \\ Emmanuel Bonnet \\ IRD: Institut de recherche pour le developpement \\ Manuela De Allegri \\ Heidelberg University \\ Adamson Sinjani Muula ( $\sim$ amuula@medcol.mw) \\ University of Malawi and The Kamuzu University of Health Sciences https://orcid.org/0000-0003-4412-9773
}

\section{Research Article}

Keywords: Universal Health Coverage, healthcare, healthcare, egalitarian

Posted Date: July 26th, 2021

DOI: https://doi.org/10.21203/rs.3.rs-700640/v1

License: (c) (i) This work is licensed under a Creative Commons Attribution 4.0 International License. Read Full License

Version of Record: A version of this preprint was published at International Journal for Equity in Health on February 18th, 2022. See the published version at https://doi.org/10.1186/s12939-022-01624-5. 


\section{Abstract}

Background: Malawi is one of a handful of countries that had resisted the implementation of user fees, showing a commitment to providing free healthcare to its population even before the concept of Universal Health Coverage (UHC) acquired global popularity. Several evaluations have investigated the effects of key policies, such as the essential health package or performance-based financing, in sustaining and expanding access to quality health services in the country. Understanding the distributional impact of health spending over time due to these policies has received limited attention. Our study fills this knowledge gap by assessing the distributional incidence of public and overall health spending between 2004 and 2016.

Methods: We relied on a Benefit Incidence Analysis (BIA) to measure the socioeconomic inequality of public and overall health spending on curative services and institutional delivery across different health facility typologies. We used data from household surveys and National Health Accounts. We used a concentration index (Cl) to determine the health benefits accrued by each socioeconomic group.

Results: Socioeconomic inequality in both public and overall health spending substantially decreased over time, with higher inequality observed in overall spending, non-public health facilities, curative health services, and at higher levels of care. Between 2004 and 2016, the inequality in public spending on curative services decreased from a $\mathrm{Cl}$ of 0.037 (SE 0.013 ) to a $\mathrm{Cl}$ of 0.004 (SE 0.011). Whiles, it decreased from a Cl of 0.084 (SE 0.014) to a Cl of 0.068 (SE 0.015) for overall spending in the same period. For institutional delivery, inequality in public and overall spending decreased between 2004 and 2016 from a Cl of 0.032 (SE 0.028) to a $\mathrm{Cl}$ of -0.057 (SE 0.014) and from a Cl of 0.036 (SE 0.022) to a $\mathrm{Cl}$ of 0.028 (SE 0.018), respectively.

Conclusion: Through its free healthcare policy, Malawi has reduced socioeconomic inequality in health spending over time, but some challenges still need to be addressed to achieve a truly egalitarian health system. Our findings indicate a need to increase public funding for the health sector to ensure access to care and financial protection.

\section{Background}

Ensuring equitable access to health services across all socioeconomic groups is a global challenge related to achieving Universal Health Coverage (UHC). Including UHC in the Sustainable Development Goal 3 indicates a global aspiration to ensure equitable access to quality care and health financial protection for all [1]. While UHC ranks high on the global health agenda, low-and middle-income countries, especially in sub-Saharan Africa (SSA), still face high health inequalities [2,3]. Being aware of these inequalities and the urgent need to overcome them, SSA countries and their development partners are progressively increasing investments and efforts to build and sustain more inclusive health systems.

Reforms aimed at UHC, including user fee removal policies, targeted subsidies, and performance-based financing, have been implemented across SSA with the explicit aim of reducing existing inequalities in access [4-6]. While evidence on the equity impact of these reforms is increasing, [7-9] limited information is available on whether and how implementing these reforms has altered the distributional incidence of health spending.

Following the structural adjustment programs and the Bamako initiatives in the 1980s, many African countries were pushed to introduce user fees for health services, which led to the underuse of health services, especially for vulnerable groups [10, 11]. In contrast with many sub-Saharan countries, Malawi resisted the introduction of user fees and has continued on its traditional path of free care at the point of use at public health facilities [12]. Beyond its free healthcare policy, to redress pronounced health inequities observed in Malawi's healthcare delivery system in the 1990s and early 2000s [13], the government implemented additional reforms to increase coverage of curative services and institutional delivery. From 2004, the Malawi government centered healthcare delivery around providing an Essential Healthcare Package (EHP) to guide, more specifically, both the planning and funding of healthcare provision. The health services targeted in the EHP include 
care for infectious and non-communicable diseases, reproductive health, and child health, with services intended to be provided free of charge at the point of use in public facilities. Additionally, since 2006, selected services targeting primarily maternal and neonatal health are also available free of charge in private-not-for-profit religious facilities (CHAM) contracted by the Ministry of Health through Service Level Agreements (SLA) [14].

Though the per capita health spending from all sources of funds has increased over time, the Government of Malawi faces financial constraints in financing the EHP services. In 2011, the domestic budget allocated to health was estimated at $7.2 \%$ [15], less than half of the $15 \%$ pledged by the heads of states of the African Union countries in the 2001 Abuja Declaration [16]. In the same year, public spending on health accounted for $19 \%$ of total funds, while external contributions and OOPE accounted for $74 \%$ and $7 \%$, respectively [17]. The proportion of public health expenditure to GDP was estimated at $2.5 \%$ in the fiscal year 2017/2018 [18], half of the recommended share of GDP that low-and-middle-income countries have to spend on health to achieve substantial progress in UHC [19]. For the fiscal year 2013/2014, the public financial gap to finance the EHP was estimated at USD 358 million [20]. As a consequence of the underfunding of the EHP policy, patients still incur substantial out-of-pocket payments for the services included in the EHP, hindering adequate access to care [21-25]. In particular, the underfunding of the EHP services under SLA contracts pushed some CHAM facilities to reintroduce user fees for curative services [26]. Previous studies revealed that the more affluent disproportionately use both curative services [27] and maternal services [28] and hence incur higher OOPE than the poorer segments of the population [27]. A recent study by Mchenga and colleagues indicated that OOPE caused $9.37 \%$ of households to face catastrophic health expenditure, leading to an increase of the poverty gap of almost $2.54 \%$ [29]. Though the literature indicates that the community is well aware of its health coverage rights, financial shortcomings in implementing EHP policy hamper its effectiveness [22]. Arnold and colleagues [30] have suggested that the EHP framework redesign by considering health equity gaps could lead to more equitable use of health services and reduced direct payments.

In addition to reforming the EHP, the government of Malawi has piloted results-based financing in several districts to test how the introduction of purchasing reforms could sustain other ongoing efforts and advance progress towards UHC. The Results-Based Financing for Maternal and Newborn Health (RBF4MNH) initiative was piloted in four districts (Balaka, Dedza, Mchinji, Ntcheu) between 2013 and 2018 and explicitly targeted obstetric care services through a combination of supply and demand-side incentives. The Support for Service Delivery Integration Performance-Based Incentive (SSDI-PBI) program was implemented between 2015 and 2017 in three districts (Chitipa, Nkhotakota and Mangochi). It targeted a broader range of maternal, reproductive, and child services by implementing supply-side incentives. Existing evidence suggests that the RBF4MNH initiative led to improvements in the quality of obstetric care services but yielded limited effect on the use of those services [31]. The SSDI-PBI scheme has been shown to produce remarkable changes in providing essential health services, but with a high heterogeneity across health services and health facilities [32].

A few studies have looked at the changes in health financing flows and health spending distribution across districts. A study by Borghi and colleagues explored the process of receiving and allocating funding at the district level and found that all funding sources were disproportionately allocated to wealthier districts, with OOPE being the most inequitably distributed, followed by public spending and external aid. In addition, this study revealed that the underfunding of health services at the district level and high OOPE were associated with high neonatal mortality rates [17]. Mann and colleagues [33] indicated that the increase of health financing on maternal and childcare led to reduced maternal and under-5 child mortality rates. These authors, however, reported that Malawi's high dependence on external resourcing presents a problem with the financial sustainability of healthcare. These studies, however, fall short of developing comprehensive analyses of the equity implications of Malawi's health financing policies, looking specifically at the distribution of health spending at the population level. Moreover, these studies do not explore changes over time in relation to the policy reforms rolled out in the country.

Our study aims to fill this knowledge gap by estimating the distributional incidence of both public and overall health spending (including donor and private health expenditure) on curative services and institutional delivery (childbirth at a 
health facility) at three different time points in Malawi. Our ambition was to explore how and to what extent equality in health spending evolved over time, also as a function of UHC reforms being implemented in Malawi (Fig. 1).

\section{Methods}

\section{Study design}

We applied a Benefit Incidence Analysis (BIA) to assess the distributional incidence of both public and overall health spending on curative services and institutional delivery at three time points. Public health spending refers to public subsidies allocated to health facilities for the provisions of care. Overall spending refers to all sources of health spending allocated to health facilities in terms of public spending, external support and out-of-pocket expenditure (OOPE). BIA measures whether the financial benefits of health services reach individuals across socioeconomic groups equally [34, 35]. To perform this analysis, we used data from available nationally representative household surveys and National Health Accounts (NHA) for health service utilization and health spending, respectively. Before deciding on the time points of our analysis, we first depicted (1) the health policies and interventions (Fig. 1) that were implemented in Malawi to foster progress towards universal coverage of curative and maternal services; (2) the household survey data on utilization of curative services and institutional delivery available; and (3) data on health spending on curative services and institutional delivery available. We then chose three time points for our analysis to match utilization and expenditure data by considering the implemented reforms.

\section{Data sources and variable measurement Health care utilization}

We derived our data on health care utilization from the Integrated Household Living Condition surveys (IHLCS) for curative services and the Demographic and Health Surveys (DHS) for institutional delivery. These nationally representative household surveys contain data on the utilization of curative services and institutional deliveries differentiated by provider typology and a measure of socioeconomic status (SES), allowing us to group individuals into weighted SES quintiles. Table 1 indicates the health variables we extracted from each household survey.

As a ranking variable to build socioeconomic strata, we used per capita consumption expenditure based on the total household food and non-food expenditure for IHLCS data sets and the household-wealth-index factor scores generated through the principal components analysis based on household material asset ownership for DHS data sets.

We estimated the annual visits to curative services and institutional deliveries in the study year for individuals across different socioeconomic groups. We used a binary variable for curative services indicating whether the respondent had used curative services in the previous 14 days and a binary variable for institutional delivery indicating whether a woman had delivered in a facility in the prior twelve months. Counts of curatives services were annualized to obtain yearly counts by multiplying the visits recorded for the 14-day recall period by 26 . We categorized curative services and institutional delivery by different health facilities types depending on data availability in each survey and NHA.

\section{Seasonality adjustment}

Due to seasonal variation of disease incidences and use of health services, the literature indicates that the annualized utilization of health services may be underestimated or overestimated based on the period of data collection [36]. To account for these seasonal variations, we conducted a sensitivity analysis by adjusting the utilization of curative services and institutional delivery from the household surveys by the monthly seasonal variations in the use of these services. We built a monthly seasonality index using data from the 2014-2018 Health Management Information System (HMIS). We estimated averages of monthly health care utilization reported in the HMIS between 2014 and 2018 and used these averages to calculate the monthly seasonality indices. We then accounted for seasonal variations in the utilization of 
curative services and institutional delivery using corresponding seasonality indices depending on the months for which health service utilization was reported in the household surveys.

\section{Unit cost}

We derived data on health spending from the National Health Accounts (see Fig. 1 and Table 1). We estimated the unit cost using recurrent public spending, donor spending and household OOPE from the National Health Accounts. We applied the constant unit subsidy assumption for the public and donor spending to estimate the unit subsidy at different types of health facilities. We determined the unity subsidy of each type of health service at each type of health facility by dividing the total health spending for one type of service by the total utilization of that service at this health facility. For OOPE, we relied on the constant unit cost assumption for each quintile based on the percentage of OOPE incurred by each quintile at different types of health facilities. We adjusted the OOPE across quintiles based on the works by Nakovics et al. [27] for curative services and by Chinkhumba et al.[37] for institutional delivery. The OOPE adjustment was based on the fact that the individuals belonging to different SES quintiles generally display different OOPE at different types of facilities. Hence, using a constant unit OOPE at each type of facility would overestimate the OOPE incurred by the bottom SES quintiles. The studies by Nakovics et al. [27] and Chinkhumba et al.[37] indicated that the least poor incurred approximately twice as much OOPE for curative services and one third more OOPE for institutional delivery than the poorest segment of the population. We estimated the unit cost for each quintile and each type of health service at each health facility by dividing the total OOPE incurred by that quintile for that service at the same health facility by the total utilization accrued to that quintile for that service at that health facility.

Table 1

Variables and data sources

\begin{tabular}{|c|c|c|c|c|c|}
\hline $\begin{array}{l}\text { Variables and data } \\
\text { sources }\end{array}$ & Health care providers & $\begin{array}{l}\text { Data sources } \\
\text { (years) }\end{array}$ & $\begin{array}{l}\text { NHA } \\
\text { data } \\
\text { (year) }\end{array}$ & $\begin{array}{l}\text { Additional } \\
\text { data } \\
\text { sources for } \\
\text { seasonality } \\
\text { adjustment } \\
\text { (year) }\end{array}$ & $\begin{array}{l}\text { Sources for } \\
\text { OOP unit } \\
\text { cost } \\
\text { adjustment }\end{array}$ \\
\hline \multirow{3}{*}{$\begin{array}{l}\text { Curative health service } \\
\text { utilization by adults } \\
\text { and children in the prior } \\
\text { two weeks }\end{array}$} & \multirow{3}{*}{$\begin{array}{l}\text { Public health facilities, mission } \\
\text { health facilities, and private } \\
\text { health facilities }\end{array}$} & \multirow{3}{*}{$\begin{array}{l}\text { IHLCS } \\
(2004 ; 2010 ; 2016)\end{array}$} & 2004 & \multirow{3}{*}{$\begin{array}{l}\text { HMIS } \\
(2014- \\
2018)\end{array}$} & \multirow{3}{*}{$\begin{array}{l}\text { Nakovics et } \\
\text { al. } 2020 \text { [27] }\end{array}$} \\
\hline & & & 2010 & & \\
\hline & & & 2015 & & \\
\hline \multirow{3}{*}{$\begin{array}{l}\text { Annual institutional } \\
\text { deliveries }\end{array}$} & \multirow{3}{*}{$\begin{array}{l}\text { Public hospitals, public health } \\
\text { centers, mission hospitals, } \\
\text { mission health centers, and } \\
\text { private facilities }\end{array}$} & \multirow{3}{*}{$\begin{array}{l}\text { DHS } \\
(2004 ; 2010 ; 2015)\end{array}$} & 2004 & \multirow{3}{*}{$\begin{array}{l}\text { HMIS } \\
(2014- \\
2018)\end{array}$} & \multirow{3}{*}{$\begin{array}{l}\text { Chinkhumba } \\
\text { et al. } 2017 \\
\text { [37] }\end{array}$} \\
\hline & & & 2010 & & \\
\hline & & & 2015 & & \\
\hline
\end{tabular}

\section{Analytical approach}

We computed traditional BIA by measuring only the distributional incidence of public spending and comprehensive BIA by looking at the distributional incidence of overall health spending, including public and donor subsidy allocation to facilities as well as OOPE incurred by individuals. Our choice was motivated by a wish to provide a comprehensive health system assessment, in line with the policy intention of the reforms implemented to promote and sustain increased service coverage in the country. Based on the data availability (Table 1), we decomposed our analysis by different health facility typologies for both curative services (public facilities vs faith-based facilities vs private facilities) and institutional delivery (public health centers vs public hospitals vs faith-based health centers vs faith-based hospitals vs private facilities) and each year. To determine the total financial health benefits at each type of health facility, we multiplied the unit subsidy or unit cost by the total utilization of health services at each type of health facility.

We used concentration indices to measure the degree of inequality in the distribution of public and overall health spending on curative services and institutional delivery across socioeconomic groups. The concentration index (Cl) quantifies the 
degree of wealth-related inequality and ranges from - 1.0 to +1.0. The $\mathrm{Cl}$ takes a negative (positive) value when the financial health benefit is concentrated disproportionately among the poor (least-poor). If the $\mathrm{Cl}$ is close to zero, a lower degree of inequality is present, and if it is zero, there is an absence of wealth-related inequality [35].

The standardized concentration index $\left(C_{h}\right)$ is estimated as follows [35]:

$C_{h}=\frac{2 \operatorname{Cov}\left(h_{i}, R_{i}\right)}{\mu}$

Where $h_{i}$ is the health variable (e.g. health care utilization) for individual $i, \mu$ is the mean of health variable, $R_{i}$ is individual i's fraction socioeconomic rank, and $\operatorname{Cov}\left(h_{i}, R_{i}\right)$ is the covariance.

We used convenient regression [38] to calculate the standard errors of the concentration index. The formula is:

$2 \sigma_{R}^{2}\left[\frac{h_{i}}{\mu}\right]=\alpha+\beta R_{i}+\varepsilon_{i}$

Where $2 \sigma_{R}^{2}$ is the variance of the fractional rank variable, $\beta$ is the estimator of the concentration index.

We performed a dominance test at a significance level of $5 \%$. The dominance test is used to statistically verify if a determined pro-poor or pro-least-poor distribution holds across the entire distribution of the socioeconomic variables [34, 35], especially when it is not clear if a distribution is pro-poor or pro-least-poor [39].

\section{Ethical considerations}

No ethical clearance was required by either the Ethics Committee of the Medical Faculty of the University of Heidelberg or the College of Medicine Research and Ethics Committee of the University of Malawi since the study relied exclusively on fully anonymized data from existing household surveys and National Health Accounts. We collected no primary data nor interacted with any respondents.

\section{Results}

Descriptive statistics of health service utilization by individuals belonging to different socioeconomic quintiles and the unity subsidies/costs of health services at health facility typologies included in this study are reported in the appendix.

\section{Benefit incidence of public spending on curative services}

Table 2 reports the distributional incidence of public health spending on curative services at public and CHAM health facilities. With a concentration index of $0.037(p<0.01)$, total public spending was slightly pro-least-poor in 2004 but shifted to steady equality in 2010 and 2016. By breaking down public spending at types of health facilities, public health facilities were approximately equally distributed at all years while CHAM health facilities disproportionately benefited the least poor over time with a concentration index of $0.180(p<0.010)$ in 2004, $0.190(p<0.05)$ in 2010 and $0.187(p<0.01)$ in 2016. The overall inequality and the inequality at public health facilities slightly declined over time. However, the inequality at CHAM health facilities persisted over time with insignificant variation in the range of 1 to $5.5 \%$. 
Table 2

Distribution of financial health benefits of public spending on curative services

\begin{tabular}{|c|c|c|c|c|c|c|}
\hline \multirow[t]{2}{*}{ Health care provider } & 2004 & 2010 & 2016 & $\begin{array}{l}\text { Diff } 2010- \\
2004\end{array}$ & $\begin{array}{l}\text { Diff } 2016- \\
2010\end{array}$ & $\begin{array}{l}\text { Diff } 2016- \\
2004\end{array}$ \\
\hline & $\mathrm{Cl}(\mathrm{SE})$ & $\mathrm{Cl}(\mathrm{SE})$ & $\mathrm{Cl}(\mathrm{SE})$ & $\mathrm{Cl}(\mathrm{SE})$ & $\mathrm{Cl}(\mathrm{SE})$ & $\mathrm{Cl}(\mathrm{SE})$ \\
\hline \multirow{2}{*}{$\begin{array}{l}\text { All public and CHAM health } \\
\text { facilities }\end{array}$} & $0.037^{a \star \star \star}$ & $0.028^{b}$ & $0.004^{c}$ & -0.009 & -0.024 & $-0.033^{\star \star}$ \\
\hline & $(0.013)$ & $(0.021)$ & $(0.011)$ & $(0.025)$ & $(0.024)$ & $(0.017)$ \\
\hline \multirow[t]{2}{*}{ Public health facilities } & $0.022^{c}$ & $0.014^{\mathrm{a}}$ & $-0.006^{a}$ & -0.008 & -0.020 & -0.028 \\
\hline & $(0.013)$ & $(0.023)$ & $(0.011)$ & $(0.026)$ & $(0.025)$ & $(0.017)$ \\
\hline \multirow[t]{2}{*}{ CHAM health facilities } & $0.180^{a \star \star \star}$ & $0.190^{\mathrm{a} \star \star}$ & $0.187^{a \star \star \star}$ & 0.010 & -0.003 & 0.007 \\
\hline & $(0.038)$ & $(0.089)$ & $(0.044)$ & $(0.097)$ & $(0.099)$ & $(0.058)$ \\
\hline \multicolumn{7}{|c|}{$\begin{array}{l}\text { Notes: } \mathrm{Cl}=\text { concentration index; } \mathrm{SE}=\text { standard errors; dominance test: } \mathrm{a}=\text { dominance, } \mathrm{b}=\text { non-dominance, } \mathrm{c}=\text { curves } \\
\text { cross; }\end{array}$} \\
\hline \multicolumn{7}{|c|}{$\star, \star *, \star \star \star$ statistically significant at the $10 \%, 5 \%$, and $1 \%$ levels, respectively } \\
\hline
\end{tabular}

\section{Benefit incidence of overall spending on curative services}

Table 3 reports the distributional incidence of overall spending on curative services. A general picture indicates that overall health spending on curative services disproportionately benefited the least poor except for the public health facilities in 2016 , where it was evenly distributed. The overall inequality of health spending on curative services in favor of the least poor increased by $36 \%$ between 2004 and 2010 from a Cl of $0.084(p<0.01)$ to a $\mathrm{Cl}$ of $0.114(p<0.01)$ but decreased by $40 \%$ to a $\mathrm{Cl}$ of $0.068(\mathrm{p}<0.01)$ in 2016 . When we break down the overall spending on curative services at health facility typologies, the inequality significantly decreased between 2010 and 2016 at public health facilities. The inequality at public health facilities increased by $74 \%$ between 2004 and 2010 from a Cl of $0.047(p<0.01)$ to a $\mathrm{Cl}$ of $0.082(p<0.01)$, but considerably decreased by $91 \%$ towards equality in $2016(\mathrm{Cl}=0.007$, not dominant). A similar distribution pattern of overall spending is observed at CHAM health facilities but with slight changes between years. The inequality at CHAM health facilities increased by 15\% between 2004 and 2010 from a Cl of $0.209(p<0.01)$ to a Cl of $0.241(p<0.01)$, but decreased by $19 \%$ to a Cl of $0.196(p<0.01)$ in 2016. A different picture is observed at private health services where the inequality of overall spending in favor of the least poor remained steady over time with a $\mathrm{Cl}$ of $0.275(\mathrm{p}<0.01)$ in 2004 , a $\mathrm{Cl}$ of 0.266 ( $p<$ $0.01)$ in 2010 and a Cl of $0.282(p<0.01)$ in 2016. 
Table 3

Distribution of financial health benefits of overall spending on curative services

\begin{tabular}{|c|c|c|c|c|c|c|}
\hline \multirow[t]{2}{*}{ Health care provider } & 2004 & 2010 & 2016 & $\begin{array}{l}\text { Diff } 2010- \\
2004\end{array}$ & $\begin{array}{l}\text { Diff } 2016 \text { - } \\
2010\end{array}$ & $\begin{array}{l}\text { Diff } 2016- \\
2004\end{array}$ \\
\hline & $\mathrm{Cl}$ (SE) & $\mathrm{Cl}(\mathrm{SE})$ & $\mathrm{Cl}$ (SE) & $\mathrm{Cl}$ (SE) & $\mathrm{Cl}$ (SE) & $\mathrm{Cl}$ (SE) \\
\hline \multirow[t]{2}{*}{ All health facilities } & $0.084^{\mathrm{a} \star \star \star}$ & $0.114^{a \star \star \star}$ & $0.068^{a \star \star \star}$ & 0.03 & $-0.046^{\star}$ & -0.016 \\
\hline & $(0.014)$ & $(0.021)$ & $(0.015)$ & $(0.025)$ & $(0.026)$ & $(0.021)$ \\
\hline \multirow[t]{2}{*}{ Public health facilities } & $0.047^{a \star \star \star}$ & $0.082^{a \star \star \star}$ & $0.007^{c}$ & 0.035 & $-0.075^{\star \star \star}$ & $-0.040 *$ \\
\hline & $(0.013)$ & $(0.023)$ & $(0.011)$ & $(0.027)$ & $(0.026)$ & $(0.018)$ \\
\hline \multirow[t]{2}{*}{ CHAM health facilities } & $0.209^{a \star \star \star}$ & $0.241^{\mathrm{a} \star \star}$ & $0.196^{a \star \star \star}$ & 0.032 & -0.045 & -0.013 \\
\hline & $(0.04)$ & $(0.093)$ & $(0.045)$ & $(0.102)$ & $(0.103)$ & $(0.062)$ \\
\hline \multirow{2}{*}{$\begin{array}{l}\text { Private health } \\
\text { facilities }^{+}\end{array}$} & $0.270^{a \star \star}$ & $0.266^{a \star \star \star}$ & $0.282^{a \star \star \star}$ & -0.004 & 0.016 & 0.012 \\
\hline & $(0.125)$ & $(0.083)$ & 0.034 & $(0.150)$ & $(0.090)$ & $(0.130)$ \\
\hline \multicolumn{7}{|c|}{ Note $: \mathrm{Cl}=$ concentration index $; \mathrm{SE}=$ standard errors; dominance test: $\mathrm{a}=$ dominance, $\mathrm{b}=$ non-dominance, $\mathrm{c}=$} \\
\hline
\end{tabular}

Table 4

Changes of the inequality magnitude of public and overall spending on curative services across health care provider typology

\begin{tabular}{|llllll|}
\hline $\begin{array}{l}\text { Health } \\
\text { spending }\end{array}$ & Year & $\begin{array}{l}\text { All health } \\
\text { facilities }\end{array}$ & $\begin{array}{l}\text { Public health } \\
\text { facilities }\end{array}$ & $\begin{array}{l}\text { CHAM health } \\
\text { facilities }\end{array}$ & $\begin{array}{l}\text { Private health } \\
\text { facilities }\end{array}$ \\
\hline $\begin{array}{l}\text { Public } \\
\text { spending }\end{array}$ & 2004 & Low least poor & Equal & Moderate least poor & $\mathrm{n} / \mathrm{a}$ \\
\cline { 2 - 5 } & 2010 & Equal & Equal & Moderate least poor & $\mathrm{n} / \mathrm{a}$ \\
\hline $\begin{array}{l}\text { Overall } \\
\text { spending }\end{array}$ & 2016 & Equal & Equal & Moderate least poor & $\mathrm{n} / \mathrm{a}$ \\
\hline & 2004 & Low least poor & Low least poor & Moderate least poor & Moderate least poor \\
\hline $\begin{array}{l}\text { Notes: Non-Significant Cls were considered equal, 1- -0.346: High pro-poor, -0.345-0.150: Moderate pro-poor, -0.149-0: } \\
\text { Low pro-poor, 0.346-1: High least poor, 0.150-0.345: Moderate least poor, 0-0.149: Low least poor. na: not applicable }\end{array}$ & Low least poor & Low least poor & Moderate least poor & Moderate least poor \\
\hline
\end{tabular}

Table 4 shows how the magnitude of the inequality in public and overall spending on curative services evolved across health provider typology. In general, the distribution of health spending did not change much over time; it mostly remained constant except for total public spending and overall spending at public health facilities that shifted from a low pro-least poor inequality to equality. The inequality was low at public facilities and moderate at CHAM and private facilities for both public and overall health spending.

\section{Benefit incidence of public spending on institutional delivery}

Table 5 shows the distributional incidence of public spending on institutional delivery at public health facilities (health centers and hospitals). Total public spending at public health facilities tended towards equality in 2004 and 2010 but shifted to a slight pro-poor benefit in 2015 with a concentration index of $-0.057(p<0.01)$. Public hospitals and health 
centers were pro-least poor and pro-poor, respectively, between 2004 and 2015. The pro-least-poor inequality at public hospitals declined continually over time with an inequality reduction of $13 \%$ and 50\% between 2004-2010 and 2010-2015, respectively. A different picture is observed at public health centers where the pro-poor inequality increased over time with an inequality increase of $17 \%$ and $97 \%$ between $2004-2010$ and $2010-2015$, respectively. In approximately ten years, the pro-least-poor inequality at public hospitals declined by $56 \%$, while the pro-poor inequality at public health centers increased by $140 \%$.

Table 5

Distribution of financial health benefits of public spending on institutional delivery

\begin{tabular}{|c|c|c|c|c|c|c|}
\hline \multirow[t]{2}{*}{ Health care provider } & 2004 & 2010 & 2015 & $\begin{array}{l}\text { Diff } 2010- \\
2004\end{array}$ & $\begin{array}{l}\text { Diff } 2015 \text { - } \\
2010\end{array}$ & $\begin{array}{l}\text { Diff } 2015- \\
2004\end{array}$ \\
\hline & $\mathrm{Cl}(\mathrm{SE})$ & $\mathrm{Cl}(\mathrm{SE})$ & $\mathrm{Cl}(\mathrm{SE})$ & $\mathrm{Cl}(\mathrm{SE})$ & $\mathrm{Cl}(\mathrm{SE})$ & $\mathrm{Cl}(\mathrm{SE})$ \\
\hline \multirow{2}{*}{$\begin{array}{l}\text { Public health } \\
\text { facilities }\end{array}$} & $0.032 b$ & $0.001 b$ & $-0.057 a * \star \star$ & -0.031 & $-0.058 * \star \star$ & $-0.089 * \star *$ \\
\hline & $(0.028)$ & $(0.017)$ & $(0.014)$ & $(0.029)$ & $(0.022)$ & $(0.028)$ \\
\hline \multirow[t]{2}{*}{ Public hospitals } & $0.145 a^{\star * *}$ & $0.126 a^{* * *}$ & $0.063 a^{\star \star \star}$ & -0.019 & -0.063 & -0.082 \\
\hline & $(0.047)$ & $(0.025)$ & $(0.024)$ & $(0.049)$ & $(0.035)$ & $(0.049)$ \\
\hline \multirow[t]{2}{*}{ Public health centers } & $-0.065 a^{*}$ & $-0.078 a^{\star \star}$ & 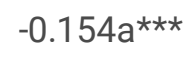 & -0.013 & $-0.076^{\star *}$ & $-0.089 * \star \star$ \\
\hline & $(0.027)$ & $(0.024)$ & $(0.018)$ & $(0.049$ & $(0.030)$ & $(0.032)$ \\
\hline
\end{tabular}

\section{Benefit incidence of overall spending on institutional delivery}

Table 6 illustrates the distributional incidence of overall spending on institutional delivery. Generally, overall spending at public and CHAM hospitals benefited the least poor women, while the overall spending at public health centers displayed a pro-poor distribution. Overall spending at CHAM health centers and private health facilities equally favored all women. The total health spending at all health facilities was evenly distributed in 2004 and 2015 but was pro-least poor in 2010 with a concentration index of $0.078(p<0.01)$. Public hospitals benefited disproportionately the least poor for all years. However, this inequality declined continually over time, by $9 \%$ between 2004 and 2010 from a $\mathrm{Cl}$ of $0.135(\mathrm{p}<0.01)$ to a $\mathrm{Cl}$ of 0.123 ( $\mathrm{p}$ $<0.01$ ) and by $40 \%$ between 2010 and 2015 to a slight pro-least poor inequality with a $\mathrm{Cl}$ of $0.074(\mathrm{p}<0.01)$. CHAM hospitals were pro-least poor in 2004 and 2010 but declined towards equality in 2015. The inequality at CHAM hospitals slightly declined by $14 \%$ between 2004 and 2010 from a Cl of $0.154(p<0.01)$ to a Cl of $0.132(p<0.01)$ and considerably declined by $82 \%$ to equality between 2010 and 2015 . The pro-poor inequality at public health centers moderately declined by $27 \%$ between 2004 and 2010 from a Cl of $-0.106(p<0.01)$ to a Cl of $-0.077(p<0.01)$ but considerably increased by $88 \%$ to a $\mathrm{Cl}$ of $-0.145(p<0.01)$ in 2015. 
Table 6

Distribution of financial health benefits of overall spending on institutional delivery

\begin{tabular}{|c|c|c|c|c|c|c|}
\hline \multirow[t]{2}{*}{ Health care provider } & 2004 & 2010 & 2015 & $\begin{array}{l}\text { Diff. 2010- } \\
2004\end{array}$ & $\begin{array}{l}\text { Diff. 2015- } \\
2010\end{array}$ & $\begin{array}{l}\text { Diff. 2015- } \\
2004\end{array}$ \\
\hline & $\mathrm{Cl}(\mathrm{SE})$ & $\mathrm{Cl}(\mathrm{SE})$ & $\mathrm{Cl}$ (SE) & $\mathrm{Cl}$ (SE) & $\mathrm{Cl}$ (SE) & $\mathrm{Cl}$ (SE) \\
\hline \multirow[t]{2}{*}{ All health facilities } & $0.036 b$ & $0.078 a^{\star \star \star}$ & $0.028 b$ & 0.042 & $-0.05^{\star}$ & -0.008 \\
\hline & $(0.022)$ & $(0.021)$ & $(0.018)$ & $(0.030)$ & $(0.027)$ & $(0.028)$ \\
\hline \multirow{2}{*}{$\begin{array}{l}\text { Public health } \\
\text { facilities }\end{array}$} & $0.033 a$ & $0.006 b$ & $-0.071 a^{\star \star \star}$ & -0.027 & $-0.077 * \star \star$ & $-0.104^{\star \star \star}$ \\
\hline & $(0.024)$ & $(0.017)$ & $(0.014)$ & $(0.029)$ & $(0.022)$ & $(0.028)$ \\
\hline \multirow[t]{2}{*}{ Public hospitals } & $0.135 a^{\star \star \star}$ & $0.123 a^{\star \star \star}$ & $0.074 a^{\star \star \star *}$ & -0.012 & -0.049 & -0.061 \\
\hline & $(0.041)$ & $(0.025)$ & $(0.025)$ & $(0.048)$ & $(0.035)$ & $(0.048)$ \\
\hline \multirow[t]{2}{*}{ Public health centers } & $-0.106 a * \star \star$ & $-0.077 a^{\star \star \star}$ & $-0.145 a^{\star \star \star}$ & 0.029 & $-0.068 * \star$ & -0.039 \\
\hline & $(0.027)$ & $(0.024)$ & $(0.018)$ & $(0.036)$ & $(0.030)$ & $(0.032)$ \\
\hline \multirow{2}{*}{$\begin{array}{l}\text { CHAM health } \\
\text { facilities }\end{array}$} & $0.121 a^{\star \star *}$ & $0.056 a$ & $-0.037 b$ & -0.065 & -0.093 & $-0.158 * \star *$ \\
\hline & $(0.042)$ & $(0.041)$ & $(0.044)$ & $(0.059)$ & $(0.060)$ & $(0.061)$ \\
\hline \multirow[t]{2}{*}{ CHAM hospitals } & $0.154 a^{\star \star \star}$ & $0.132 a^{\star *}$ & 0.024 & -0.022 & -0.108 & -0.13 \\
\hline & $(0.060)$ & $(0.067)$ & $(0.058)$ & $(0.090)$ & $(0.088)$ & $(0.083)$ \\
\hline \multirow[t]{2}{*}{ CHAM health centers } & $-0.071 a$ & $0.069 b$ & 0.091 & $0.140 *$ & 0.022 & $0.162^{\star}$ \\
\hline & $(0.053)$ & $(0.063)$ & $(0.081)$ & $(0.082)$ & $(0.104)$ & $(0.099)$ \\
\hline \multirow{2}{*}{$\begin{array}{l}\text { Private health } \\
\text { facilities }\end{array}$} & $0.102 \mathrm{a}$ & $0.099 b$ & 0.096 & -0.003 & -0.003 & -0.006 \\
\hline & $(0.113)$ & $(0.100)$ & $(0.112)$ & $(0.151)$ & $(0.151)$ & $(0.159)$ \\
\hline \multicolumn{7}{|c|}{ Note : $\mathrm{Cl}=$ concentration index $; \mathrm{SE}=$ standard errors; dominance test: $\mathrm{a}=$ dominance, $\mathrm{b}=$ non-dominance, $\mathrm{c}=$} \\
\hline \multicolumn{7}{|c|}{ concentration curve and line of equality cross; +: for private health facilities, only the OOP expenditure was included } \\
\hline \multicolumn{7}{|c|}{ 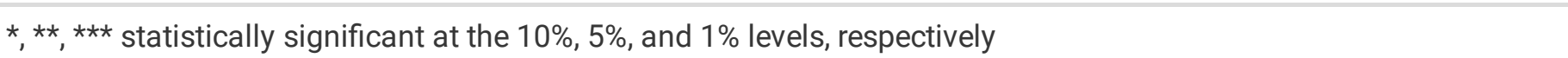 } \\
\hline
\end{tabular}

Table 7 shows the change in the magnitude of the inequality of public and overall spending on institutional delivery across health care provider typology over time. Total public spending shifted to a low pro-poor inequality in 2015 from equality in 2004 and 2010. In contrast, total overall spending oscillated from equality in 2004 to a low-least poor inequality and shifted to equality again in 2015. Public hospitals remained slightly pro-poor at all years for both public and overall spending. Public spending at public health centers shifted from a low pro-poor inequality in 2004 and 2010 to moderate pro-poor inequality in 2015, whereas overall spending at public health centers remained at a low pro-poor inequality at all years. The inequality of overall spending at CHAM hospitals decreased continually from a moderate least poor inequality in 2004, though low-least poor inequality in 2010 to equality in 2015. Overall spending at CHAM health centers and private health facilities remained equal at all years. 
Table 7

Changes of the inequality magnitude of public and overall spending on institutional delivery across health care provider

\begin{tabular}{|c|c|c|c|c|c|c|c|c|c|}
\hline $\begin{array}{l}\text { Health } \\
\text { spending }\end{array}$ & Year & $\begin{array}{l}\text { All } \\
\text { health } \\
\text { facilities }\end{array}$ & $\begin{array}{l}\text { Public } \\
\text { health } \\
\text { facilities }\end{array}$ & $\begin{array}{l}\text { Public } \\
\text { hospitals }\end{array}$ & $\begin{array}{l}\text { Public } \\
\text { health } \\
\text { centers }\end{array}$ & $\begin{array}{l}\text { CHAM } \\
\text { health } \\
\text { facilities }\end{array}$ & $\begin{array}{l}\text { CHAM } \\
\text { hospitals }\end{array}$ & $\begin{array}{l}\text { CHAM } \\
\text { health } \\
\text { centers }\end{array}$ & $\begin{array}{l}\text { Private } \\
\text { health } \\
\text { facilities }\end{array}$ \\
\hline \multirow[t]{3}{*}{$\begin{array}{l}\text { Public } \\
\text { spending }\end{array}$} & 2004 & Equal & Equal & $\begin{array}{l}\text { Low } \\
\text { least } \\
\text { poor }\end{array}$ & $\begin{array}{l}\text { Low pro- } \\
\text { poor }\end{array}$ & $\mathrm{n} / \mathrm{a}$ & $\mathrm{n} / \mathrm{a}$ & $\mathrm{n} / \mathrm{a}$ & $\mathrm{n} / \mathrm{a}$ \\
\hline & 2010 & Equal & Equal & $\begin{array}{l}\text { Low } \\
\text { least } \\
\text { poor }\end{array}$ & $\begin{array}{l}\text { Low pro- } \\
\text { poor }\end{array}$ & $\mathrm{n} / \mathrm{a}$ & $\mathrm{n} / \mathrm{a}$ & $\mathrm{n} / \mathrm{a}$ & $\mathrm{n} / \mathrm{a}$ \\
\hline & 2015 & $\begin{array}{l}\text { Low pro- } \\
\text { poor }\end{array}$ & $\begin{array}{l}\text { Low pro- } \\
\text { poor }\end{array}$ & $\begin{array}{l}\text { Low } \\
\text { least } \\
\text { poor }\end{array}$ & $\begin{array}{l}\text { Moderate } \\
\text { pro-poor }\end{array}$ & $\mathrm{n} / \mathrm{a}$ & $\mathrm{n} / \mathrm{a}$ & $\mathrm{n} / \mathrm{a}$ & $\mathrm{n} / \mathrm{a}$ \\
\hline \multirow[t]{3}{*}{$\begin{array}{l}\text { Overall } \\
\text { spending }\end{array}$} & 2004 & Equal & Equal & $\begin{array}{l}\text { Low } \\
\text { least } \\
\text { poor }\end{array}$ & $\begin{array}{l}\text { Low pro- } \\
\text { poor }\end{array}$ & $\begin{array}{l}\text { Low least } \\
\text { poor }\end{array}$ & $\begin{array}{l}\text { Moderate } \\
\text { least } \\
\text { poor }\end{array}$ & Equal & Equal \\
\hline & 2010 & $\begin{array}{l}\text { Low } \\
\text { least } \\
\text { poor }\end{array}$ & Equal & $\begin{array}{l}\text { Low } \\
\text { least } \\
\text { poor }\end{array}$ & $\begin{array}{l}\text { Low pro- } \\
\text { poor }\end{array}$ & Equal & $\begin{array}{l}\text { Low } \\
\text { least } \\
\text { poor }\end{array}$ & Equal & Equal \\
\hline & 2015 & Equal & $\begin{array}{l}\text { Low pro- } \\
\text { poor }\end{array}$ & $\begin{array}{l}\text { Low } \\
\text { least } \\
\text { poor }\end{array}$ & $\begin{array}{l}\text { Low pro- } \\
\text { poor }\end{array}$ & Equal & Equal & Equal & Equal \\
\hline
\end{tabular}

The seasonality analysis indicated no statistically significant changes to our analysis - meaning that the seasonal variations in health service utilization had no impact on the socioeconomic distribution of annualized curative services and institutional delivery included in our study.

\section{Discussion}

Our study presents the results of a quasi-longitudinal analysis assessing the distributional incidence of both public and overall health spending on curative services and institutional delivery in Malawi at three periods. The study provides the first assessment of the distribution of health spending across socioeconomic groups at different types of health facilities in Malawi. Three key findings emerge from our analysis. First, we observe increased equality in the distribution of public and overall health spending over time for both curative services and institutional delivery. Second, the distributional incidence of public spending tended to be more egalitarian than overall spending throughout the study period. Third, both public and overall spending were more egalitarian for institutional delivery than for curative services, more egalitarian at public than at private health facilities, and more egalitarian at lower levels of care (e.g., health centers) than at the higher level of care (e.g., hospitals).

We note that public spending was egalitarian and became increasingly so over time which is not aligned with findings from several prior studies conducted in other LMICs, where public spending has repeatedly been observed to benefit disproportionately the least poor for both curative services [2, 40-42] and institutional delivery [43]. This observation suggests that free care policy at the point of use in Malawi is likely to have fostered equality in distributing public spending for curative and institutional delivery services. The free care at public facilities and CHAM facilities through SLA contracts with the Malawi government has likely translated into the steady increase of the use of curative [26] and maternal $[44,45]$ services. Similar findings were reported by two studies conducted in India, which revealed that the introduction of the 
Janani Suralesha Yojana (JSY) policy enabling access to institutional delivery free of charge fostered equality in public health spending $[46,47]$. Considering that the widespread reach of the free healthcare policy was achieved through direct contracting of CHAM facilities, our findings corroborate the already existing evidence on the importance of investing in policies that build on public-private partnerships. In contexts where the reach of public facilities is constrained, setting up such partnerships represents an essential step to ensure greater equality in both health care use and distribution of public health spending [48].

Nonetheless, we note that while becoming more egalitarian over time, the distribution of overall spending remained proleast-poor for curative services but not for institutional delivery. This finding is consistent with findings from Ghana [49] and South Africa [50], but not from Tanzania [51], where overall health spending was also observed to be equally distributed. The persistent OOPE can probably explain this remaining inequality even in the presence of a formal free healthcare policy $[27,29]$. The fact that inequality was observed mostly at non-public facilities is aligned with prior literature suggesting that OOPE in Malawi is driven mainly by people re-directing demand towards private services when human resources and medical supplies are absent at public facilities $[22,24]$. The fact that this inequality is less dominant for institutional delivery is likely due to the introduction of SLA in 2006, enabling private not-for-profit facilities to provide maternal care free of charge. This fostered increased equal access to care for delivering women $[44,45]$ and possibly also to introducing the two PBF programs, both of which had a strong focus on maternal and reproductive health services [31]. Hence, our observation is likely due to the higher OOPE associated with using curative services compared to institutional delivery. In the current study, the share of OOPE incurred by the top quintile group for using curative services compared to the share of the bottom quintile group is approximately $67 \%$ higher than the share of OOPE incurred by making use of institutional delivery. People still incur some OOPE for curative health services in Malawi due to the persistently high prevalence of HIV and its concurrent infections, the emergence of high-cost treatment for non-communicable diseases, and the introduction of fees in private wards [26] in response to chronic underfunding of the EHP [22, 23, 27, 52]. Therefore, our findings call for removing instead of introducing financial barriers at the point of care, especially for the poorer segments of the population [53]. Also, the increasing public and donor funding should be channelled towards sustaining the implementation of the EHP and expanding SLAs to include services other than maternal care as the only means to increase accessibility to free care for curative services.

Confirming previous results from low-and-middle-income countries [54-56], we identified a noticeably higher inequality at higher levels of care (e.g., hospital) for both curative services and institutional delivery. Across SSA, higher-level health facilities are concentrated in urban areas, often only accessible to the least poor, given the higher direct and indirect costs of seeking care at this level [57], including considerable transport costs [58-60]. For instance, a study by Nakovics and colleagues [27] indicated that transport costs in Malawi represent as much as $43 \%$ of the total cost of care. Our findings indicate the need for action on the supply-side by increasing the density of secondary level facilities and on the demandside by introducing reimbursements for transport costs to overcome existing inequalities due to geographical disparities [58].

\section{Methodological considerations}

Despite its value as the first study to explore the distributional incidence of health spending in Malawi, we recognize that our study has some limitations. First, DHS and IHLCS household surveys contain different information to allow for the classification of individuals across socioeconomic groups. We used consumption expenditure and material asset ownership to classify the individuals in socioeconomic quintiles for IHLCS and DHS, respectively. The resulting socioeconomic groups may not be fully comparable across IHLC and DHS surveys. However, we assume that any potential difference may be insignificant since prior research has indicated how in low-income countries like Malawi, the magnitude of household consumption expenditures mirrors households' ownership of material assets [61, 62]. Second, based on the data at our disposal, having applied the constant unit subsidy assumption, we might have masked differences in financial

Page $12 / 19$ 
health benefits accruing to people of different socioeconomic status or living in different geographical settings. Third and last, our study does not account for differential health care needs across socioeconomic groups (horizontal equity) nor differences in the age, gender and quality of the services received. For more decomposition of the socioeconomic inequality in health spending in Malawi, further analysis relying on comprehensive data including health care needs, age, gender and the quality of health services is needed.

\section{Conclusion}

Though the inequality in health spending on curative services and institutional delivery in Malawi has decreased over time, our study depicts that disparities in the distribution of public and overall health spending persist. Malawi's critical challenge is that of reducing or eliminating the out-of-pocket payments that still hinder poorer segments of the population from using health services. The establishment of an EHP ensuring the provision of essential services free of charge at the point of use represents a first critical step in ensuring access to care across all population groups. However, insufficient funding,

reflected in a scarcity of human and material resources, challenges its effective implementation. Hence, greater investments enabling effective implementation are needed to tackle persisting inequalities in healthcare access to foster greater equality in health benefits.

\section{Abbreviations}

BIA: Benefit Incidence Analysis

CHAM: Christian Health Association of Malawi

Cl: Concentration Index

DHS: Demographic and Health Surveys

EHP: Essential Health Package

IHLCS: Integrated Household Living Condition Surveys

NHA: National Health Accounts

OOPE: Out-Of-Pocket Expenditure

RBF4MNH: Results-Based Financing for Maternal and Newborn Health

SLA: Service-Level Agreements

SSA: Sub-Saharan Africa

SSDI-PBI: Support for Service Delivery Integration Performance-Based Incentive

UHC: Universal Health Coverage

USD: United States Dollar

\section{Declarations}

\section{Acknowledgements}


The authors thank the Ministry of Health and the National Statistics Office in Malawi for making the household surveys publicly available and for sharing the National Health Accounts data used for this study. The authors are grateful to staff from the Agence Française de Développement, particularly Cecilia Poggi and Anda David, for their technical and scientific support. The authors also appreciate John Ataguba and Bona Chitah for their contribution in defining the analytical framework and Takondwa Mwase for supporting the data acquisition.

\section{Funding}

The Agence Française de Développement funded this study through the EU-AFD Research Facility on Inequalities, which received the financial assistance of the European Union (a delegation agreement no. DCI-HUM-2017/386-943). The content of this manuscript is solely the responsibility of the authors and does not necessarily reflect the official position of the European Union or the Agence Française de Développement.

\section{Conflict of interest}

The authors declare no conflict of interest.

\section{Authors' contribution}

MDA, VR and EB conceived the study and defined its conceptual design. MR and AM acquired data. MDA, MR, and EY defined the analytical strategy. MR and EY cleaned the data and carried out the analysis with support from MDA. All authors critically contributed to the interpretation of the findings. MR drafted the manuscript with support from all authors. All authors read, edited, and approved the final manuscript.

\section{Availability of data and materials}

The original datasets from DHS (http://dhsprogram.com/) and IHLCS (https://microdata.worldbank.org/) are freely available. The original datasets from NHA are available from the corresponding author upon reasonable request and with permission of Malawi's Ministry of Health.

\section{References}

1. Kruk ME, Gage AD, Arsenault C, Jordan J, Leslie HH, Rode-DeWan S, et al. High-quality health systems in the Sustainable Development Goals era: time for a revolution. Lancet Glob Health. 2018; 6(11): e1196-1252. https://doi.org/10.1016/S2214109X(18)30386-3.

2. Wagstaff A, Bredenkamp C, Buisman LR. Progress on Global Health Goals: Are the Poor Being Left Behind? World Bank Research Observer. 2014; 29(2): 137-162. https://doi.org/10.1093/wbro/lku008.

3. Yaya S, Ghose B. Global Inequality in Maternal Health Care Service Utilization: Implications for Sustainable Development Goals. Health Equity. 2019; 3(1): 145-154. https://doi.org/10.1089/heq.2018.00.

4. Bloom DE, Khoury A, Subbaraman R. The promise and peril of universal health care. Science. 2018; 361(6404): eaat9644. https://doi.org/10.1126/science.aat9644 .

5. Gwatkin, D.R. and A. Ergo, Universal health coverage: friend or foe of health equity? Lancet. 2011; 377(9784): $2160-1$. https://doi.org/10.1016/S0140-6736(10)62058-2 .

6. Hunter BM, Horrison S, Portela A, Bick D. The effects of cash transfers and vouchers on the use and quality of maternity care services: A systematic review. PLoS One. 2017; 12(3): e0173068. https://doi.org/10.1371/journal.pone.0173068 . 
7. Binyaruka P, Robberstad B, Torsvik G, Gorghi J. Who benefits from increased service utilisation? Examining the distributional effects of payment for performance in Tanzania. Int J Equity Health. 2018; 17(1):14. https://doi.org/10.1186/s12939-018-0728-x.

8. Calhoun LM, Speizer IS, Guilkey D, Bukusi E. The Effect of the Removal of User Fees for Delivery at Public Health Facilities on Institutional Delivery in Urban Kenya. Maternal and Child Health Journal. 2018; 22(3):409-18. https://doi.org/10.1007/s10995-017-2408-7.

9. Nguyen TH, Zombré D, Ridde V, De Allegri M. The impact of reducing and eliminating user fees on facility-based delivery: a controlled interrupted time series in Burkina Faso. Health Policy and Planning. 2018; 33(8):948-56. https://doi.org/10.1093/heapol/czy077.

10. Ridde V, Girard JE. Twelve years after the Bamako initiative: facts and political implications for equity in health services accessibility for indigent Africans. Sante Publique. 2004; 16(1): 37-51. https://doi.org/10.3917/spub.041.0037.

11. Thomson M, Kentikelenis A, Stubbs S. Structural adjustment programmes adversely affect vulnerable populations: a systematic-narrative review of their effect on child and maternal health. Public Health Rev. 2017; 38:13.

https://doi.org/10.1186/s40985-017-0059-2.

12. Makwero MT. Delivery of primary health care in Malawi. Afr J Prim Health Care Fam Med. 2018; 10(1): 1799. https://doi.org/10.4102/phcfm.v10i1.1799.

13. Zere E, Moeti M, Kirigia J, Mwase T, Kataika E. Equity in health and healthcare in Malawi: analysis of trends. BMC Public Health. 2007; 7:78. https://doi.org/10.1186/1471-2458-7-78.

14. Chirwa ML, Kazanga I, Foedo G, Thomas S. Promoting universal financial protection: contracting faith-based health facilities to expand access-lessons learned from Malawi. Health Res Policy Syst. 2013; 11:27.

https://doi.org/10.1186/1478-4505-11-27.

15. Kanyuka M, Ndawala J, Mleme T, Chisesa L, Makwemba M, Amouzou A, et al. Malawi and Millennium Development Goal 4: a Countdown to 2015 country case study. Lancet Glob Health. 2016; 4(3): e201-14. https://doi.org/10.1016/S2214109X(15)00294-6.

16. World Health Organization. The Abuja Declaration: Ten Years On. Geneva, Switzerland; 2011. https://www.who.int/healthsystems/publications/abuja_report_aug_2011.pdf?ua=1. Accessed: 20 Nov 2020.

17. Borghi J, Munthali S, Million LB, Martinez-Alvarez. Health financing at district level in Malawi: an analysis of the distribution of funds at two points in time. Health Policy Plan. 2018; 33(1): 59-69. https://doi.org/10.1093/heapol/czx130 .

18. World Bank. Malawi Public Expenditure Review 2019: Putting Fiscal Policy on a Sustainable Path. Washington DC: World Bank; 2019. https://openknowledge.worldbank.org/handle/10986/33047. Accessed: 20 Nov 2020.

19. Mcintyre D, Meheus F, Røttingen JA. What level of domestic government health expenditure should we aspire to for universal health coverage? Health Econ Policy Law. 2017, 12(2): 125-137. https://doi.org/10.1017/S1744133116000414.

20. O'Hare B, Curtis M. Health spending, illicit financial flows and tax incentives in Malawi. Malawi Med J. 2014; 26(4):1337.

21. Ministry of Health. Malawi Health Sector Strategic Plan2011-2016. Lilongwe: Malawi; 2012. https://www.resakss.org/sites/default/files/Malawi\%20MH\%202011\%20Malawi\%20Health\%20 Sector\%20Strategic\%20Plan\%202011\%20-\%202016.pdf. Accessed: 18 Dec 2020.

Page $15 / 19$ 
22. Abiiro GA, Mbera GB, De Allegri M. Gaps in universal health coverage in Malawi: a qualitative study in rural communities. BMC Health Serv Res. 2014; 14:234. https://doi.org/10.1186/1472-6963-14-234.

23. Bowie C, Mwase T. Assessing the use of an essential health package in a sector wide approach in Malawi. Health Res Policy Syst. 2011; 9: 4. https://doi.org/10.1186/1478-4505-9-4.

24. Mueller DH, Lungu D, Acharya A, Palmer N. Constraints to implementing the Essential Health Package in Malawi. PLoS One. 2011; 6(6): e20741. https://doi.org/10.1371/journal.pone.0020741.

25. Wang Q, Brenner S, Leppert G, Banda TH, Kalmus O, De Allegri M. Health seeking behaviour and the related household out-of-pocket expenditure for chronic non-communicable diseases in rural Malawi. Health Policy Plan. 2015; 30(2): $242-52$. https://doi.org/10.1093/heapol/czu004.

26. Watson SI, Wroe EB, Dunbar EL, Mukherjee J, Squire SB, Nazimera L, et al. The impact of user fees on health services utilization and infectious disease diagnoses in Neno District, Malawi: a longitudinal, quasi-experimental study. BMC Health Serv Res. 2016; 16(1): 595. https://doi.org/10.1186/s12913-016-1856-x.

27. Nakovics MI, Brenner S, Bongololo G, Chinkhumba J, Kalmus O, Leppert G, et al. Determinants of healthcare seeking and out-of-pocket expenditures in a "free" healthcare system: evidence from rural Malawi. Health Econ Rev. 2020; 10 (1): 14. https://doi.org/10.1186/s13561-020-00271-2.

28. Yaya S, Bishwajit G, Shah S. Wealth, education and urban-rural inequality and maternal healthcare service usage in Malawi. BMJ Glob Health. 2016, 1(2): e000085. http://dx.doi.org/10.1136/bmjgh-2016-000085.

29. McHenga M, Chirwa GC, Chiwaula LS. Impoverishing effects of catastrophic health expenditures in Malawi. Int J Equity Health. 2017; 16(1): 25. https://doi.org/10.1186/s12939-017-0515-0.

30. Arnold M, Nkhoma D, Griffin S. Distributional impact of the Malawian Essential Health Package. Health Policy Plan. 2020; 35(6): 646-56. https://doi.org/10.1093/heapol/czaa015.

31. Brenner S, Mazalale J, Wilhelm D, Nesbitt RC, Lohela TJ, Chinkhumba J, et al. Impact of results-based financing on effective obstetric care coverage: evidence from a quasi-experimental study in Malawi. BMC Health Serv Res. 2018; 18(1):791. https://doi.org/10.1186/s12913-018-3589-5.

32. Brenner S, Chase RP, McMahon A, Lohmann J, Makwero CJ, Muula AS, et al. Effect Heterogeneity in Responding to Performance-Based Incentives: A Quasi-Experimental Comparison of Impacts on Health Service Indicators Between Hospitals and Health Centers in Malawi. Health Syst Reform. 2020; 6(1): e1745580. https://doi.org/10.1186/s12939-021014489.

33. Mann C, Ng C, Akseer N, Bhutta ZA, Borghi J, Colbourn T, et al. Countdown to 2015 country case studies: what can analysis of national health financing contribute to understanding MDG 4 and 5 progress? BMC Public Health. 2016; 16 Suppl 2:792. https://doi.org/10.1186/s12889-016-3403-4.

34. McIntyre D, Ataguba JE. How to do (or not to do) ... a benefit incidence analysis. Health Policy Plan. 2011; 26(2):174-82. http://dx.doi.org/10.1093/heapol/czq031.

35. O'Donnell O, van Doorslaer E, Wagstaff A, Lidelow M. Analyzing health equity using household survey data: A guide to techniques and their implementation. Bull World Health Organ. 2008; 86(10): 816.

http://dx.doi.org/10.2471/BLT.08.052357.

36. Ataguba JE. Socioeconomic inequality in health service utilisation: Does accounting for seasonality in health-seeking behaviour matter? Health Econ, 2019. 28(11): p. 1370-1376. https://doi.org/10.1002/hec.3925. 
37. Chinkhumba J, De Allegri M, Mazalale J, Brenner S, Mathanga D, Muula AS, et al. Household costs and time to seek care for pregnancy related complications: The role of results-based financing. PLoS One. 2017, 12(9): e0182326. https://doi.org/10.1371/journal.pone.0182326.

38. Kakwani N, Wagstaff A, van Doorslaer E. Socioeconomic inequalities in health: measurement, computation, and statistical inference. J Econ. 1997; 77(1): 87-103. https://doi.org/10.1016/S0304-4076(96)01807-6.

39. Davoodi HE, Tiongson ER, Asawanuchit SS. Benefit incidence of Public Education and Health Spending Worldwide: Evidence from a New Data Base. Poverty and Public Policy. 2010; 2(2): 5-52. https://doi.org/10.2202/1944-2858.1055.

40. World Bank. World Development Report 2004: Making Services Work for Poor People. Washington DC: World Bank, 2004.

41.Castro-Leal F, Dayton J, Demery L, Mehra K. Public spending on health care in Africa: do the poor benefit? Bull World Health Organ. 2000; 78(1): 66-74.

42. Huber E, Nielsen F, Pribble J, Stephens JD. Politics and Inequality in Latin America and the Caribbean. American Sociological Review. 2006; 71(6): 943-63. https://www.jstor.org/stable/25472438.

43. Ensor T, Nadjib M, Quayyum Z, Megraini A. Public funding for community-based skilled delivery care in Indonesia: to what extent are the poor benefiting? Eur J Health Econ. 2008; 9(4): 385-92. http://dx.doi.org/10.1007/s10198-007-0094-x.

44. Manthalu G, Yi D, Farrar S, Nkhoma D. The effect of user fee exemption on the utilization of maternal health care at mission health facilities in Malawi. Health Policy Plan. 2016; 31(9): 1184-92. http://dx.doi.org/10.1093/heapol/czw050.

45. Zeng W, Sun D, Mphwanthe H, Huan T, Nam JE, Saint-Firmin P, et al. The impact and cost-effectiveness of user fee exemption by contracting out essential health package services in Malawi. BMJ Glob Health. 2019; 4(2):e001286. http://dx.doi.org/10.1136/bmjgh-2018-001286.

46. Bowser D, Patenaude B, Bhawalkar M, Duran D, Berman P. Benefit incidence analysis in public health facilities in India: utilization and benefits at the national and state levels. Int J Equity Health. 2019; 18(1): 13. https://doi.org/10.1186/s12939019-0921-6.

47. Srivastava S, Bose M, Karan A, Selvaraj S. Benefit Incidence Analysis of institutional child delivery in India, 2004-2014: Improving equity through the National Health Mission? BMJ Global Health. 2016; 1(Suppl 1): A4.2-A4A5. http://dx.doi.org/10.1136/bmjgh-2016-EPHPabstracts.5.

48. Joudyian N, Doshmangir L, Mahdavi M, Tabrizi JS, Gordeev VS. Public-private partnerships in primary health care: a scoping review. BMC Health Serv Res. 2021; 21(1): 4. https://doi.org/10.1186/s12913-020-05979-9.

49. Akazili J, Garshhong B, Aikins M, Gyapong J, Mclntyre D. Progressivity of health care financing and incidence of service benefits in Ghana. Health Policy Plan. 2012, 27 Suppl 1: i13-22. https://doi.org/10.1093/heapol/czs004.

50. Ataguba JE, Mclntyre D. Paying for and receiving benefits from health services in South Africa: is the health system equitable? Health Policy Plan. 2012; 27 Suppl 1: i35-45. https://doi.org/10.1093/heapol/czs005.

51. Mtei G, Makawia S, Ally M, Kuwawenaruwa A, Meheus F, Borghi J. Who pays and who benefits from health care? An assessment of equity in health care financing and benefit distribution in Tanzania. Health Policy Plan. 2012; 27 Suppl 1: i23-34. https://doi.org/10.1093/heapol/czs018.

52. Wang Q, Brenner S, Kalmus O, Banda HT, De Allegri M. The economic burden of chronic non-communicable diseases in rural Malawi: an observational study. BMC Health Serv Res. 2016; 16: 457. https://doi.org/10.1186/s12913-016-1716-8. 
53. Louart S, Bonnet E, Ridde E. Is patient navigation a solution to the problem of "leaving no one behind"? A scoping review of evidence from low-income countries. Health Policy and Planning. 2021; 36(1): 101-16.

https://doi.org/10.1093/heapol/czaa093.

54. Anselmi L, Lagarde M, Hanson K. Equity in the allocation of public sector financial resources in low- and middle-income countries: a systematic literature review. Health Policy Plan. 2015; 30(4): 528-45. https://doi.org/10.1093/heapol/czu034.

55. Asante A, Price J, Hayen A, Jan S, Wiseman V. Equity in Health Care Financing in Low- and Middle-Income Countries: A Systematic Review of Evidence from Studies Using Benefit and Financing Incidence Analyses. PLoS One. 2016; 11(4): e0152866. https://doi.org/10.1371/journal.pone.0152866.

56. Mahal A, Singh J, Afridi F, Lamba V, Gumber A, Selvaraju V. Who benefits from public health spending in India? Washington D.C: World Bank; 2001.

http://documents1.worldbank.org/curated/en/930041468285004372/pdf/563710WP0publi10Box349502B01PUBLIC1.pdf. Accessed: 14 Jan 2021.

57. O'Donnell O. Access to health care in developing countries: breaking down demand side barriers. Cadernos de Saude Publica. 2007; 23: 2820-34. https://doi.org/10.1590/s0102-311x2007001200003.

58. Lohela TJ, Campbell OMR, Gabrysch S. Distance to care, facility delivery and early neonatal mortality in Malawi and Zambia. PLoS One. 2012; 7(12): e52110. https://doi.org/10.1371/journal.pone.0052110.

59. Mazalale J, Kambala C, Brenner S, Chinkhumba J, Lohmann J, Mathanga DP, et al. Factors associated with delivery outside a health facility: cross-sectional study in rural Malawi. TropMed Int Health. 2015; 20(5): 617-26. https://doi.org/10.1111/tmi.12473.

60. Kukla M, McKay N, Rheinganz R, Harman J, Schumacher J, Kotloff KL, et al. The effect of costs on Kenyan households' demand for medical care: why time and distance matter. Health Policy Plan. 2017; 32(10): 1397-1406. https://doi.org/10.1093/heapol/czx120.

61. Morris SS, Calogero C, Hoddinott J, Christiaensen LJM. Validity of rapid estimates of household wealth and income for health surveys in rural Africa. J Epidemiol Community Health. 2000; 54(5): 381-7. http://dx.doi.org/10.1136/jech.54.5.381.

62. Ucar B. The Usability of Asset Index as an Indicator of Household Economic Status in Turkey: Comparison with Expenditure and Income Data. Social Indicators Research: An International and Interdisciplinary Journal for Quality-of-Life Measurement, Springer. 2015; 121(3): 745-60. https://doi.org/10.1007/s11205-014-0670-2.

\section{Figures}




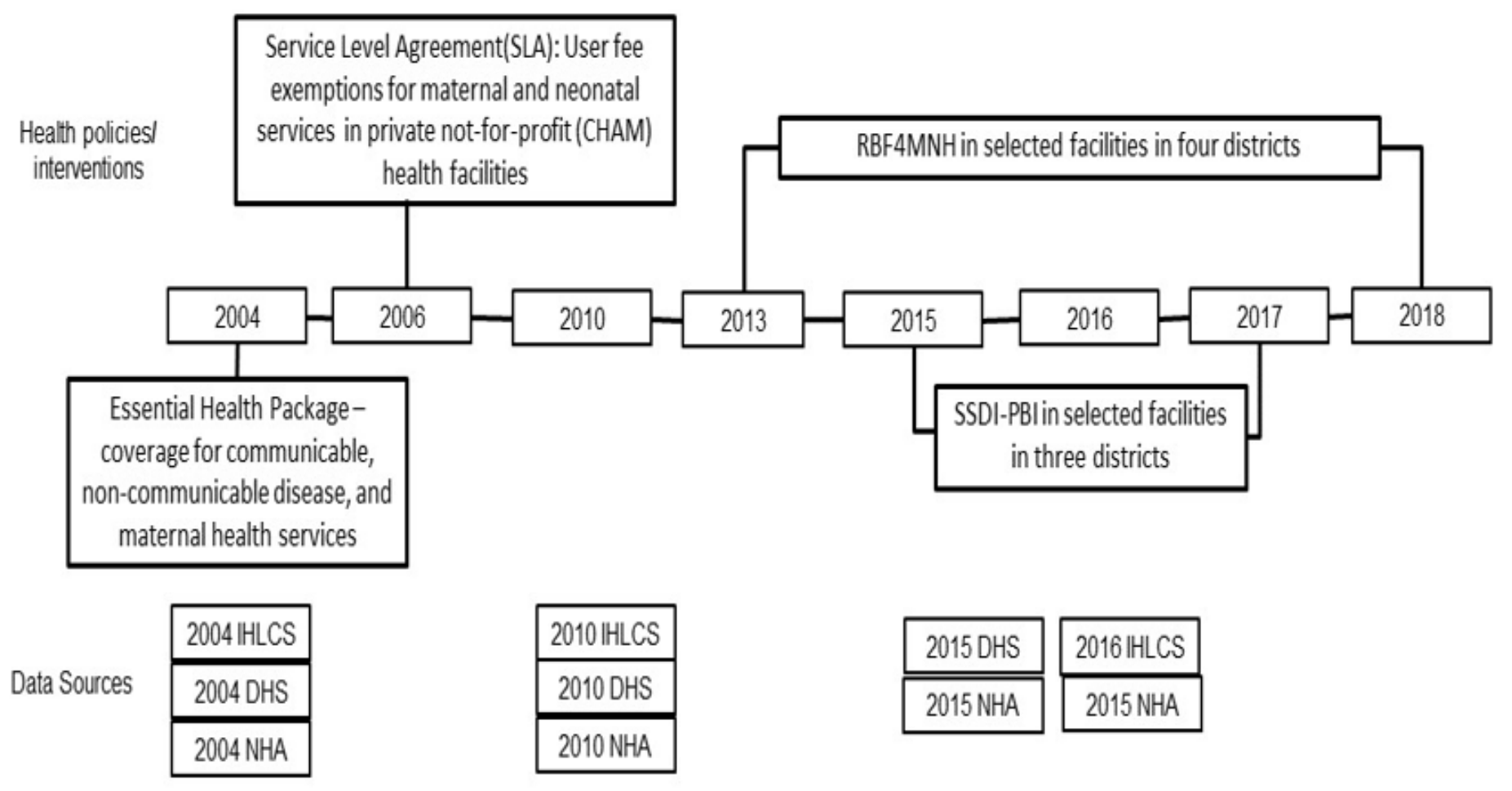

\section{Figure 1}

Timeline of health policies and interventions targeting curative and maternal services in Malawi

\section{Supplementary Files}

This is a list of supplementary files associated with this preprint. Click to download.

- Appendix.docx 